\title{
Radionuclide Shuntography for the Evaluation of Ventriculo-Peritoneal Shunt in Children with Hydrocephalus
}

\section{Jawa $\mathrm{ZM}^{1}$, Mahmud $\mathrm{MR}^{2}$, Aruah $\mathrm{SC}^{3}$, and Ismaila $\mathbf{A}^{1}$}

${ }^{1}$ Department of Nuclear Medicine, National Hospital Abuja, Abuja, Nigeria

${ }^{2}$ Neurosurgery Unit, National Hospital Abuja, Abuja, Nigeria

${ }^{3}$ Department of Radiotherapy and Oncology, National Hospital Abuja, Abuja, Nigeria

*Corresponding author: Jawa ZM, Department of Nuclear Medicine and Radiology, National Hospital Abuja, Nuclear Medicine, Garki Abuja, fct 234, Nigeria. Tel: 2348039667929, 2348089731111; Fax: 234666777888; E-mail: jawazm@yahoo.com

Received date: September 29, 2016; Accepted date: October 27, 2016; Published date: November 03, 2016

Copyright: (C) 2016 Jawa ZM, et al. This is an open-access article distributed under the terms of the Creative Commons Attribution License, which permits unrestricted use, distribution, and reproduction in any medium, provided the original author and source are credited.

\section{Abstract}

Background: Radionuclide shuntography is a safe, simple and non-invasive functional imaging technique for determining ventriculo-peritoneal ( $\mathrm{V}-\mathrm{P})$ shunts tube patency with minimal radiation exposure. This is particularly useful in children with hydrocephalus in whom V-P shunt is inserted to divert CSF drainage.

V-P shunts are, in many cases, permanent treatment option for children with hydrocephalus and radionuclide shuntography is becoming a very popular technique because of the increasing numbers and survival of children with shunt-treated hydrocephalus.
\end{abstract}

Objective: The aim of this study is to document the usefulness of shuntography in the evaluation of V-P shunt in patients with hydrocephalus.

Materials and Methods: All shuntograms performed in our institution from 2008 to 2015 were included in this study. Radionuclide shuntography was performed with Tc-99m DPTA injected into the shunt reservoir and images acquired using a dual headed MEDISO camera. A normal shuntogram is considered as free flow of radiotracer (Tc-99m DTPA) from site of injection to the distal end of shunt tube and spillage into the peritoneum.

Results: A total of 56 children were studied comprising of 32 males and 24 females with age ranges of 5 month to 11 years. Different patterns of results were found, normal functioning shunt tube, partial block shunt tube due to infection or inflammatory debris and total blocked shunt tube due to mechanical defects.

Conclusion: About $52 \%$ of our patients had partial blockage of their shunt tube. Patients who are diagnosed with a partial tube blockage will require only flushing of the tube and antibiotics treatment, while mechanically blocked tube will require shunt revision. This distinction is critical considering the cost of replacement of V-P shunt tube and the manpower time for surgery. There was no mortality or morbidity associated with radionuclide shuntography in our patients.

Keywords: Shuntography; Cerebrospinal fluid; Hydrocephalus; V-P shunt tube

\section{Introduction}

Hydrocephalus is a disease that is cause by disturbance of cerebrospinal fluid (CSF) production, flow or absorption, leading to accumulation of CSF in the cerebral ventricles. The clinical manifestation of hydrocephalus depends on the patient's age, type of hydrocephalus and duration of obstruction. However, the clinical manifestations in infants include progressive enlargement of the head with cranio-fascial disproportion, irritability, headaches, vomiting and spasticity [1,2]. Surgical shunt insertion is the mainstay of management of patients with hydrocephalus [3].

Shunts are most often permanent treatment option for patients with hydrocephalus [3-5]. Shunt tubes consist of a proximal catheter, reservoir with a valve system, and distal catheter [6,7]. The proximal tube is inserted into the lateral ventricle, while the reservoir is placed subcutaneously overlying the mastoid bone and the distal catheter tunneled to drain into, any body cavity capable of fluid reabsorption such as the peritoneum, pleura, atrium or gall bladder [8,9]. Most neurosurgeons prefer ventriculo-peritoneal shunts (V-P shunt) because of less complications and easy access to the peritoneum [10]. The incidence of V-P shunt malfunction in the first lyear ranges from $25 \%$ to $40 \%$ and $63 \%$ to $70 \%$ at 10 years [11]. Malfunction rates with ventriculo-atrial and ventriculo-pleural shunts are slightly higher [12]. V-P shunt malfunction may be due to a partial (infection / inflammatory debris) or a total (mechanical) or obstruction. Partial obstruction occurs usually within 6month post V-P shunt insertion and mainly due to infection with Staphylococcus aureus and Staphylococcus epidermidis [13]. The intracranial catheter may also be seeded in the setting of bacterial meningitis $[13,14]$. The incidence of infection of ventriculoperitoneal shunts was approximately $8 \%$ to $10 \%$ in large trials [15]. Mechanical failure of the valvular system within the 
Citation: Jawa ZM, Mahmud MR, Aruah SC, Ismaila A (2016) Radionuclide Shuntography for the Evaluation of Ventriculo-Peritoneal Shunt in Children with Hydrocephalus. J Nucl Med Radiat Ther 7: 315. doi:10.4172/2155-9619.1000315

Page 2 of 4

reservoir or kinking of the tube causes total obstruction. This usually occurs 2 years post tube insertion $[16,17]$.

The assessment of shunt function is critical to the care of patient with hydrocephalus in whom shunt tube has been inserted. The diagnosis of shunt malfunction may be challenging, the clinical presentation of a malfunctioning shunt is often nonspecific, especially in young children. The initial evaluation of shunt tube malfunction may be done with radiological modalities such as X-rays, ultrasound scan or CT/MRI. However, these modalities are not specific and often equivocal in cases of shunt malfunction $[18,19]$. Numerous procedures have been proposed to evaluate shunt function. Such as, response to digital compression of the flushing device [20], injection of contrast media [21,22] and radionuclide directly into the shunt device $[23,24]$ into the lateral ventricle $[25,26]$ or indirectly into the lumbar subarachnoid space [26,27] ultrasound flowmetres [28] and thermosensitive procedures [27], These modalities are invasive and carry a significant risk to the patient. Radionuclide shuntograpy has proven to be safe, simple and no-invasive functional imaging technique that can be used to evaluate shunt function. Radionuclide shuntography involves the injection of a small dose of radionuclide into the reservoir shunt tube and image acquisition using a gamma camera.

\section{Materials and Methods}

All shuntograms performed in our department between 2008 and 2016 were included in this study. We included all children diagnosed with hydrocephalus in which a V-P shunt was inserted to divert CSF; they were aged between 5 month to 11 years. Patient's cooperation is highly required for the success of this technique. Our patients were made comfortable. The patients were placed in the supine position with the head turned away from the shunt site. The skin over the reservoir is cleaned with methylated spirit. An insulin syringe containing $1 \mathrm{ml}$ of Tc-99mDTPA (equivalent to $37 \mathrm{MBq}$ ) is injected into the reservoir portion at an acute angle. Dynamic images were acquired for 20 mins using a dual headed MEDISO camera. The patients were kept in the same position; the time of peritoneal spillage is recorded. If there was no peritoneal spill noted at $20 \mathrm{~min}$, static images were acquired at $1 \mathrm{~h}, 3 \mathrm{~h}$ and $6 \mathrm{~h}$.

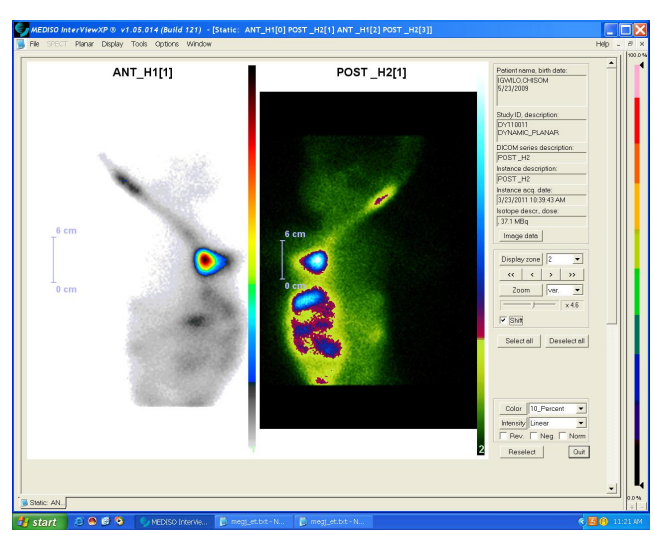

Figure 1: Normal functioning V-P shunt tube, the entire is visualized and there is free spillage of radioactivity into the peritoneal cavity.
A normal shuntogram is considered as free flow of radiotracer from site of injection to the distal end of shunt tube with evidence of spillage into the peritoneal cavity within $20 \mathrm{~min}$ (Figure 1).

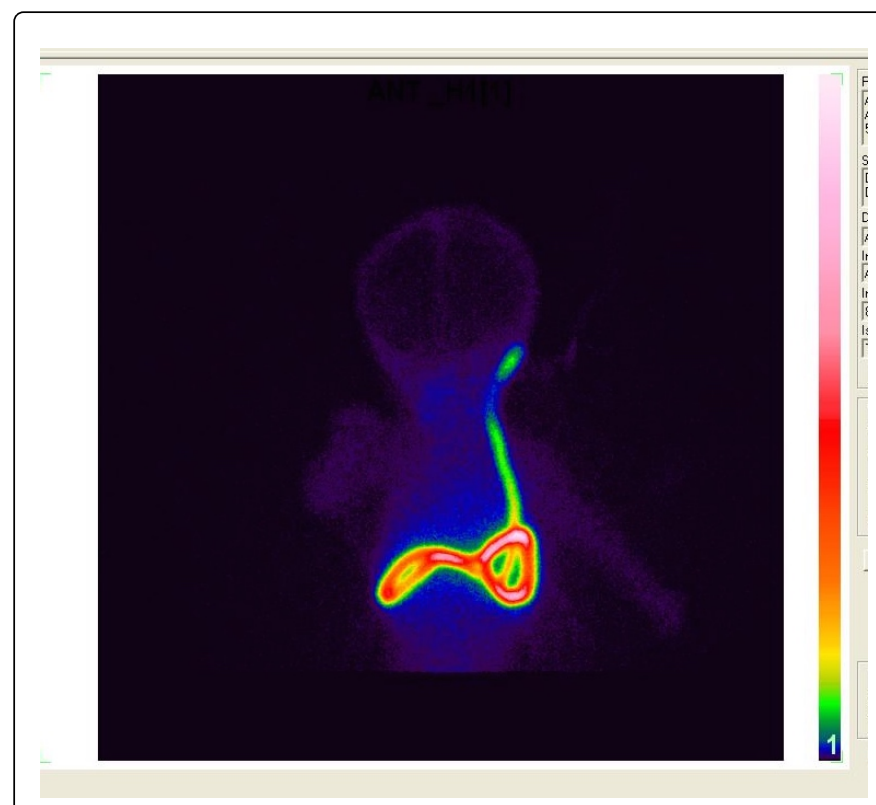

Figure 2: Showing a partial blocked V-P shunt, radioactivity is seen outlining the entire tube, but no spillage.

In a partially blocked tube, the entire tube is visualized down to the tip, but there will be delayed spillage up to about $6 \mathrm{~h}$ (Figure 2), while a total blocked tube will show abrupt termination of tube activity at site of blockage usually at the proximal part of the tube and no evidence of spillage into the peritoneal cavity after $6 \mathrm{~h}$ of imaging (Figure 3 ).

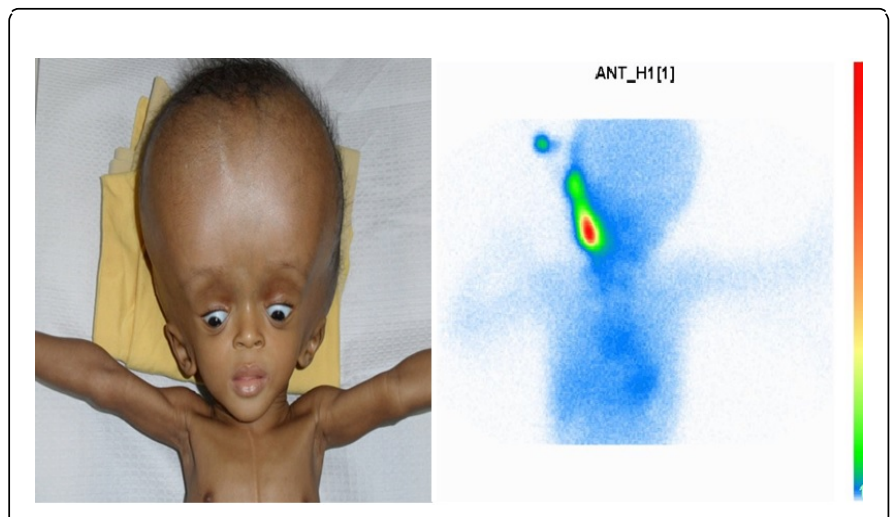

Figure 3: Showing a total block V-P tube (mechanical) due to malfunction of the reservoir system. Radiotracer is not seen beyond the reservoir.

After care following radionuclide shuntography is critical in order to avoid complications such as puncture of reservoir, extravasations of radioactivity, bleeding, infection and CSF pseudocyst [29].

All our patients were observed in the department for $3 \mathrm{~h}$ to $6 \mathrm{~h}$ and followed up. 


\section{Results}

A total of 56 children were studied (32 males and 24 females) with age ranges between 5 months to 11 years. Different patterns of results were observed: normal functioning shunt tube; total blocked shunt tube due to mechanical defects; partial blocked shunt tube due to infection or inflammatory debris and overflow of CSF. We did not record any mortality or morbidity in our patients. Table 1 shows results of our findings.

\begin{tabular}{|l|l|}
\hline Findings & Number of cases \\
\hline Normal functioning & $18(32 \%)$ \\
\hline Partial Obstruction & $29(52 \%)$ \\
\hline Total Obstruction & $7(13 \%)$ \\
\hline Inconclusive/suboptimal study & $2(3 \%)$ \\
\hline Total & 56 \\
\hline
\end{tabular}

Table 1: Findings of radionuclide shuntography.

\section{Discussions}

Ventriculo-peritoneal shunts tube insertion is usually a permanent treatment option for children with hydrocephalus [3-5]. There is an increase in number of V-P shunts insertion worldwide this is because of the increasing survival of children with shunt-treated hydrocephalus $[4,5]$. Radionuclide shuntography is becoming a very popular imaging technique in evaluating V-P shunt tube function, this is because, it is safe, non-invasive, cost- effective and with minimal radiation burden $[5,6]$.

The evaluation of the function of a V-P shunt tube may be challenging especially in young children, this is because the signs and symptoms of shunt malfunction are nonspecific and overlap with symptoms of other illnesses especially acute viral disease [11,12]. Radiological tools such as X-ray, ultrasound scan and CT could be used as an initial tool to evaluate shunt function, however, these modalities have low specificity for diagnosis [28-30].

Radionuclide shuntography offers an alternative, cheap, noninvasive and simple functional diagnostic modality for the evaluation of shunt function.

A total of 56 children were studied this include of 32 males and 24 females with age ranges between 5 months to 11 years. Different patterns of results were found, normal functioning shunt, total blocked tube due to mechanical defects, partial block tube due to infection or inflammatory debris and overflow of CSF. There were normal functioning shunt tubes in $32 \%$ of our patient population. A total of 29 (52\%) demonstrated partial obstruction of the distal end of their tubes; these patients subsequently had flushing of the tubes and antibiotics therapy. When compared with previous studies, [2,17]. Our percentage for partial obstruction due to infection is higher; this is because the incidence of infection is higher in the tropics due to poor standard of leaving, poverty and ignorance.

Total obstruction of shunt tube due to mechanical failure and kinking of tube was found in 7 (13\%) of our patients. In these patients, removal and replacement of the V-P shunt tube was carried out by the neurosurgeons. In our study group, there were $2(3 \%)$ patients in whom the study was declared inclusive. On these occasions, the children were uncorporative and radiotracer was mis-injected.

There is no existing protocol for radionuclide shuntography. However, we recommend that critical attention to details, observation of strict aseptic technique and close collaboration between the Nuclear medicine physician, Pediatricians and Neurosurgeons would improve the diagnostic accuracy and minimize complication of radionuclide shuntography.

\section{Limitations and Recommendations}

The limitations of our study include a small number of patients and the fact that we did not select our patients according to signs or symptoms of tube malfunction, instead, we included all patient who were referred to us to for assessment of shunt tube patency and function. We recommend further study with a larger number of patients, and also selecting and subdividing patients according to their signs and symptoms of tube malfunction.

\section{Conclusion}

Radionuclide shuntography is increasingly becoming a popular imaging tool amongst neurosurgeons and pediatricians in evaluating V-P shunt tube in patient with hydrocephalus because it is safe, noninvasive, cost- effective and with minimal radiation burden. About $52 \%$ of our patients with suspected V-P shunt tube malfunction had partial tubal blockage. Patients who are diagnosed with a partial tube blockage will require only flushing of the tube and antibiotics treatment, while mechanically block tube will require replacement. This distinction is critical considering the cost of replacement of tube and manpower time for surgery. There was no mortality or morbidity associated with radionuclide shuntography in our patients.

\section{References}

1. Garton HJ, Kestle JR, Drake JM (2001) Predicting shunt failure on the basis of clinical symptoms and signs in children. J Neurosurg 94: 202-210.

2. Drake JM, Kestle JR, Tuli S (2000) CSF shunts 50 years on--past, present and future. Childs Nerv Syst 16: 800-804.

3. Lette J, Douesnard JM, Léveillé J, Ouaknine G, Marchand L, et al. (1986) A reproducible radionuclide procedure for measurement of cerebrospinal fluid shunt flow. Eur J Nucl Med 12: 240-243.

4. May CH, Aurisch R, Kornrumpf D, Vogel S (1999) Evaluation of shunt function in hydrocephalic patients with the radionuclide $99 \mathrm{mTc}$ pertechnetate. Childs Nerv Syst 15: 239-244.

5. Browd SR, Gottfried ON, Ragel BT, Kestle JR (2006) Failure of cerebrospinal fluid shunts. Part II. Overdrainage, loculation, and abdominal complications. Pediatr Neurol 34: 171-176.

6. Goeser CD, McLeary MS, Young LW (1998) Diagnostic imaging of ventriculoperitoneal shunt malfunctions and complications. Radiographics 18: 635-651.

7. Lollis SS, Mamourian AC, Vaccaro TJ, Duhaime AC (2010) Programmable CSF shunt valves: radiographic identification and interpretation. AJNR Am J Neuroradiol 31: 1343-1346.

8. Sood S, Ham SD, Canady AI (2001) Current treatment of hydrocephalus. Neurosurgery Q 11: 36-44.

9. Ellegaard L, Mogensen S, Juhler M (2007) Ultrasound-guided percutaneous placement of ventriculoatrial shunts. Childs Nerv Syst 23: 857-862.

10. Garton HJ (2004) Cerebrospinal fluid diversion procedures. J Neuroophthalmol 24: 146-155. 
Citation: Jawa ZM, Mahmud MR, Aruah SC, Ismaila A (2016) Radionuclide Shuntography for the Evaluation of Ventriculo-Peritoneal Shunt in Children with Hydrocephalus. J Nucl Med Radiat Ther 7: 315. doi:10.4172/2155-9619.1000315

Page 4 of 4

11. Browd SR, Ragel BT, Gottfried ON, Kestle JR (2006) Failure of cerebrospinal fluid shunts. Part I. Obstruction and mechanical failure. Pediatr Neurol 34: 83-92.

12. Arnell K, Eriksson E, Olsen L (2003) Asymptomatic shunt malfunction detected fortuitously by observation of papilloedema. Acta Neurochir (Wien) 145: 1093-1096.

13. Udayasankar UK, Braithwaite K, Arvaniti M, Tudorascu D, Small WC, et al. (2008) Low-dose nonenhanced head CT protocol for follow-up evaluation of children with ventriculoperitoneal shunt: reduction of radiation and effect on image quality. AJNR Am J Neuroradiol 29: 802-806.

14. Gower DJ, Gower VC, Richordson SH, Kelly DL (1985) Reduced bacterial adherence to silicone plastic neurosurgical prosthesis. Pediatr Neurosci 12: $127-133$.

15. Gardner P, Leipzig T, Phillips P (1985) Infections of central nervous system shunts. Med Clin North Am 69: 297-314.

16. Schoenbaum SC, Gardner P, Shillito J (1975) Infections of cerebrospinal fluid shunts: epidemiology, clinical manifestations, and therapy. J Infect Dis 131: 543-552.

17. Cuka GM, Hellbusch LC (1995) Fractures of the peritoneal catheter of cerebrospinal fluid shunts. Pediatr Neurosurg 22: 101-103.

18. Morishita A, Nagashima T, Kurata H, Eguchi T, Tamaki N (2002) Clinical analysis of pediatric shunt catheter fracture. No Shinkei Geka 30: 839-845

19. Kurlander GJ, Chua GT (1967) Roentgenology of ventriculo-atrial shunts for the treatment of hydrocephalus. Am J Roentgenol Radium Ther Nucl Med 101: 157-167.

20. Blair K, Aucoin R, Kloiber R, Molnar CP (1989) The complementary role of plain radiographs and radionuclide shuntography in evaluating CSFVP shunts. Clin Nucl Med 14: 12-13.
21. Iskandar BJ, Sansone JM, Medow J, Rowley HA (2004) The use of quickbrain magnetic resonance imaging in the evaluation of shunt-treated hydrocephalus. J Neurosurg 101: 147-151.

22. Kast J, Duong D, Nowzari F, Chadduck WM, Schiff SJ (1994) Timerelated patterns of ventricular shunt failure. Childs Nerv Syst 10: 524-528.

23. Borgbjerg BM, Gjerris F, Albeck MJ, Hauerberg J, Borgesen SV (1998) A comparison between ventriculo- peritoneal and ventriculo-atrial cerebrospinal fluid shunts in relation to rate of revision and durability. Acta Neurochir (Wien) 140: 459-464.

24. Rekate HL (2007) Treatment of hydrocephalus in adults. Neurosurg Focus 22: 1 .

25. Dewey RC, Kosnik EJ, Sayers MP (1976) A simple test of shunt function: the shuntgram. Technical note. J Neurosurg 44: 121-126.

26. Graham P, Howman-Giles R, Johnston I, Besser M (1982) Evaluation of CSF shunt patency by means of technetium-99m DTPA. J Neurosurg 57: 262-266.

27. Matin P, Goodwin DA, DeNardo GL (1970) Cerebrospinal fluid scanning and ventricular shunts. Radiology 94: 435-438.

28. Flitter MA, Buchheit WA, Murtagh F, Lapayowker MS (1975) Ultrasound determination of cerebrospinal fluid shunt patency. Technical note. J Neurosurg 42: 728-730.

29. Brereton RJ (1980) The value of an ultrasonic flowmeter in assessing the function of CSF shunts. J Pediatr Surg 15: 68-73.

30. Katz DM, Trobe JD, Muraszko KM, Dauser RC (1994) Shunt failure without ventriculomegaly proclaimed by ophthalmic findings. J Neurosurg 81: 721-725. 